\title{
El bagre partido, de Antonio Salinas
}

César Augusto Espino León*

cael_85@hotmail.com

Universidad Nacional Federico Villarreal

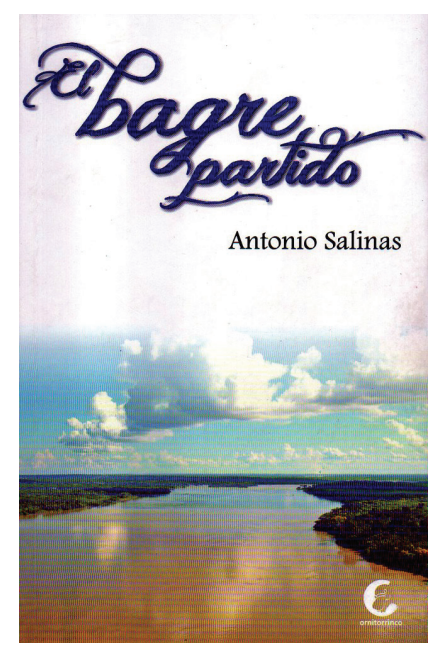

El bagre partido

Antonio Salinas

ISBN: 978-612-46565-0-7

Lima: Ornitorrinco Editores

Año: 2013, 164 pp.

Cin duda, uno de los mayores referentes literarios en Chimbote ha sido y es Antonio $\checkmark$ Salinas (Lima, 1944 - París, 1997). Para ofrecer unas pistas sobre la trayectoria de este importante autor, se puede mencionar que perteneció al Grupo de Literatura Isla Blanca de Chimbote. Se cuenta, además, que en 1974 se estableció en Francia de manera definitiva, sin descuidar por ello su labor literaria. Siguió escribiendo con tenacidad y, en 1984, el jurado

* César Augusto Espino León es egresado de la especialidad de Literatura por la Universidad Nacional Federico Villarreal. Ha participado como invitado en la tertulia literaria "Aullidos" (2011) realizada en la ciudad de Trujillo junto a otros jóvenes escritores. Se ha desempeñado como ponente en el Coloquio Anual de Estudiantes de Literatura de la UNFV en el 2013 y en el III y IV Coloquio Internacional de Literaturas Amazónicas. Colabora habitualmente en el blog "Textura Artefacto" y en la Revista peruana de literatura. Ha publicado diferentes artículos en revistas de universidades tanto nacionales como extranjeras. Por el momento, trabaja como docente y elabora su tesis de licenciatura. 
del Premio Copé lo declaró finalista en la categoría de cuento por "Noche de brujos". Un año más tarde, en 1985, publicó El bagre partido. Tras su muerte, aparecieron sus crónicas de viajes bajo el título Embarcarse en la nostalgia (1999) y el libro de cuentos Verdenegro alucinado moscón (2000) ${ }^{1}$.

No obstante, es gracias al libro de cuentos titulado El bagre partido ${ }^{2}$, hoy vuelto en circulación gracias a Ornitorrinco Editores, que Salinas se ha hecho merecedor de la posición que mencionamos. Mediante este libro, Salinas demuestra una excepcional calidad literaria, debido al uso de una escritura férrea, sencilla y violenta. En las siguientes líneas se destacará el valor de esta colección de cuentos desde algunas oportunidades de interpretación que, en la medida de nuestras posibilidades, creemos que puede ofrecer.

\section{La transversalidad de la categoría del testimonio}

Q uizá la propuesta más importante de El bagre partido radique en la construcción de un testimonio ficcional coherente con sucesos reales y dolorosos para un sector del país. De esa forma, en los diversos momentos del relato se representa la violencia política y la represión militar en auge dentro de la zona costeńa. Más exactamente, se sitúa en el gobierno militar de Juan Velasco Alvarado ("el Gobierno Revolucionario") y en cómo ceñía la libertad de muchos pueblos al hacer trabajar al Estado en conjunto con los militares para poder dar "orden" al "caos".

¿Qué otros elementos podrían justificar una ubicación de la categoría del testimonio en El bagre partido? Bien se podría mencionar las escenas escalofriantes y el uso de un lenguaje violento con los que el narrador relata cada masacre, cada represión y se mimetiza como testigo clave de estas situaciones violentas que se dan en varios de los cuentos como "Los diablos de Huanca", "Los de la línea 25" o "Los eternos". Se puede hablar, al mismo tiempo, de las interrupciones angustiosas alrededor de los relatos. Así, por ejemplo, en "Los ataúdes de mi padre”, se percibe lo dicho anteriormente:

\footnotetext{
1 Aunque, muy aparte de esta faceta como narrador, otro dato significativo es la existencia de poemas suyos que aún permanecen inéditos.

2 Existe una edición anterior a esta aparecida en el año 1985, a través del sello Lluvia Editores, con una tirada de 1,000 ejemplares. La edición anterior contiene una frase de Henry Miller y los cuentos de dicho texto.
} 
Pero sí me acuerdo de aquella noche en que me despertaron y sin saber dónde, me llevaron con ellos. (...) A mí me parecía verlos serios pero contentos, yo estaba alegre viendo cómo se iba formando la casa. No sé a qué hora me quedé dormido en la arena, aquí, en mi casa. Sí, yo los he visto, (...), los cachacos disparaban sin asco, ¡tatatata! ¡Al suelo! ¡Tírense al suelo! ¡tatatata!. A la mañana siguiente teníamos un rancho de esteras de totora. (Salinas, 2013, pp. 60-61)

Como se puede colegir de la cita anterior, el narrador mismo se constituye como un sujeto adolorido, sufrido, angustiado y neutralizado por las acciones de las fuerzas del orden. Ha observado la forma en que los cachacos ${ }^{3}$ asesinan a las personas, transformando la naturaleza chimbotana en una suerte de campo de concentración. Es así que El bagre partido de Salinas se configura como un testimonio desde la ficción debido a que se propone "un desentrañamiento de la realidad, tomando los hechos principales, los que más han afectado la sensibilidad de un pueblo" (Barnet, 1986, p. 288).

\section{Los cuentos de El bagre partido}

$\mathrm{E}$ libro contiene siete cuentos relacionados a temas sociales y políticos como la pobreza, la migración, el esfuerzo, el homicidio, la represión, entre otros. Sin embargo, lo rescatable y resaltante en el autor es su preocupación por presentarnos espacios ficcionales y diversos, puesto que sus cuentos no solo presentan una atmósfera de la capital o de la costa peruana, sino también de la sierra (Huancayo) y de la selva (Amazonas). A continuación, hablaremos de dichos espacios.

El primer cuento titulado "Rosenda" nos presenta aspectos de la convivencia entre la protagonista homónima y Antonio. Los acontecimientos se dan en la capital limeña donde se muestra una naturaleza gris y lluviosa. Estos elementos tristes y lúgubres serán fieles acompañantes de los personajes. Antonio es un personaje que adolece de úlceras y que vive bajo una sombra de inactividad, todo lo contrario es Rosenda, ella vive de la libertad,

Es una jeringonza, así se le dice a los soldados o fuerzas militares del orden en el Perú.

4 Lo citado en el texto pertenece a Miguel Barnet y fue extraído de La fuente viva. Sin embargo, ese artículo se puede encontrar en Testimonio y literatura, The Society for the Study of Contemporary Hispanic and Lusophone Revolutionary Literatures, 1986. 
de las diversiones, pero a pesar de eso, padece de problemas sociales. Mantiene, a su vez, una postura desencantada y severa al momento de comparar a los poderosos y humildes que conviven en la capital del país:

Y en Lima, (...) la gran capital de ese Perú antiguo, la capital que quiso reemplazar al Cusco, ahí están los señores de vientre prominente haciendo girar la rueda, condenando a los que quieren seguir el juego, los parios a un lado, los dioses al otro, hay que saber vivir, sí, hay que saber vivir (...). (Salinas, 2013, p. 36)

La protagonista critica a los poderosos y esa imagen se refleja en su padre. Este último personaje es retratado como un hombre bohemio que, a pesar de ser adinerado, no cumple a cabalidad los estatus sociales de la clase alta, sino todo lo contrario, se emborracha y transgrede todo comportamiento occidental. Al final, Rosenda, desesperada y angustiada por todas las situaciones acontecidas, decide irse del cuarto que compartía con Antonio, perdiéndose a los lejos.

El segundo cuento, titulado "Los de la Línea 25", se ambienta en la capital. El caos prima en dicho espacio, mientras la heterogénea afluencia de personas que viajan en la Línea 25 está a la orden del día, tanto para ir al trabajo como cualquier otro destino. El narrador recae en el conductor del bus, quien describe, con fluida agudeza, a estos pasajeros mientras suben y bajan del vehículo. Así, mientras describe una urbe subdesarrollada, el narrador observa cómo se propician cotidianamente los malos hábitos entre los limeños:

La multitud baja por delante dándose empujones, mientras los que esperan suben por la puerta de atrás. Por el retrovisor puedo observar el sacrificio por subir, las palabras sueltas de: ¡Permiso!, ¡No empujen!, ¡Disculpe! ¡Ay! El vehículo no está lleno, tiene capacidad para recibir muchas personas más, pero es esa maldita costumbre de los capitalinos de querer subir todos al mismo tiempo. (Salinas, 2013, pp. 44-45)

Presenciar este comportamiento por parte del narrador-personaje, permitirá entrever las percepciones de su mundo interior ante una multitud de personas que asiste al ómnibus. El cuento se nutre, además, de los monólogos interiores derivados de 
diversos estados emocionales del protagonista al verse envuelto en una inesperada y tensa intervención policial. Si bien podría tratarse de la representación de un sujeto migrante, no acostumbrado al movimiento desordenado, rápido y violento de la capital, un análisis más incisivo ayudaría a rastrear mejor un posible lugar de enunciación.

En el tercer cuento, "Los ataúdes de mi padre", la temática de la migración se hace presente de un modo más claro. Precisamente, aborda problemas surgidos en una forma de organización humana como es la invasión (propia de los procesos migratorios que se dieron en la capital). De igual forma, se intercalan los tiempos del relato y del espacio (sierra y costa). Así, la situación económica apremia a la familia de Don Faustino, quien tiene que convertirse en el fabricante de ataúdes del pueblo. A esto se suman los problemas originados en la formación de comités:

Pronto estuvimos en una pampa blanca, la arena era suave y tibia, la noche clara como el día y en el cielo la luna redonda. Había mucha gente que murmuraba y oí que le dijeron a mi padre: "Tú no estás en el comité de invasión y no has dado tu cuota, así es que acomódate por ahí”. (Salinas, 2013, p. 60)

El cuarto cuento titulado "Los eternos" guarda cierta asemeja con el primero ("Rosenda"), ya que los protagonistas sienten un cariño recíproco. En esta ocasión, entran a tallar Ricardo y Lucía, quienes se buscan para expresar sus sentimientos, pues para ellos el amor rompe barreras y no hay quien permita transgredir sus ideales. De esa forma, el sentimiento parece prevalecer a lo largo de su despliegue retórico. Sin embargo, mientras avanza dicho intercambio de palabras afectuosas, estas empiezan a tomar la forma de una persuasión para participar en un posible escenario de resistencia violenta. Así como se debe cuidar y luchar por el amor, Ricardo propone una lucha por las tierras que ha de defender:

Ven, mi amor, a ser feliz, ven que debemos defender nuestro amor, Lucía, el amor será invencible si peleamos juntos. Ven, Lucía, no debemos quedarnos a morir sin posibilidad de defendernos. Vámonos a las cordilleras que allí tenemos a nuestro dios Pachacámac, allí tenemos nuestra lluvia y nuestras planicies. (Salinas, 2013, p. 87) 
Seguidamente, en el quinto cuento, “Teresa, los Sánchez y el último domingo”, la representación de la situación económica que vive el país es grave. Sus protagonistas, los hermanos Carlos y Lalo Sánchez, pasan por un momento en el que quieren emerger de la miseria, pero la situación económica del país no es buena. Aunque lo resaltante son las escenas violentas por parte del oficial de un patrullero que ha repelido una manifestación y ha capturado terroristas. Después, el sexto cuento, "Los diablos de Huanca”, las masacres descritas por parte de los soldados hacia personas que realizaban un mitin, son escalofriantes. Las fuerzas del orden propugnan un estado de violencia y de dominación, apoyados por los periódicos del país que no informan ningún acontecimiento. Los medios comunicativos han sido repelidos y neutralizados.

Por último, en el cuento que da título al texto, "El bagre partido", el narradorpersonaje relata algunos recuerdos de la capital mientras navega por el río Amazonas. Aquí, lo más logrado del relato es la facilidad y fluidez con que dichas reminiscencias son relacionadas, una a una, con cada tramo del viaje. De ese modo, estos monólogos interiores revelan gradualmente el estado anímico del personaje al punto que compara el medio ambiente asfixiante con una casa de citas del Callao.

En conclusión, lo que Antonio Salinas muestra en su libro de cuentos son las diversas situaciones por las cuales vio atravesar el país, pero no de una manera soslayada o mediante un proceso lento de recuperación, sino todo lo contrario. Manifiesta una actitud negativa hacia un país en el que todavía no existe el mínimo respeto entre semejantes. $\mathrm{Y}$ al mismo tiempo, presenta una esperanza que desespera y produce angustias no solo personales sino también de nivel económico, político y militar. 